\title{
Promiscuous, non-catalytic, tandem carbohydrate-binding modules modulate the cell-wall structure and development of transgenic tobacco (Nicotiana tabacum) plants
}

\author{
Olawole O. Obembe $\cdot$ Evert Jacobsen $\cdot$ Jaap Timmers • \\ Harry Gilbert · Anthony W. Blake · J. Paul Knox • \\ Richard G. F. Visser · Jean-Paul Vincken
}

Received: 14 February 2007/ Accepted: 7 May 2007/Published online: 11 July 2007

C) The Botanical Society of Japan and Springer 2007

\begin{abstract}
We have compared heterologous expression of two types of carbohydrate binding module (CBM) in tobacco cell walls. These are the promiscuous CBM29 modules (a tandem CBM29-1-2 and its single derivative CBM29-2), derived from a non-catalytic protein1, NCP1, of the Piromyces equi cellulase/hemicellulase complex, and the less promiscuous tandem CBM2b-1-2 from the Cellulomonas fimi xylanase 11A. CBM-labelling studies revealed that CBM29-1-2 binds indiscriminately to every tissue of the wild-type tobacco stem whereas binding of CBM2 $-1-2$ was restricted to vascular tissue. The promiscuous $\bar{C}$ BM29-1-2 had much more pronounced effects on transgenic tobacco plants than the less promiscuous CBM2b-1-2. Reduced stem elongation and prolonged juvenility, resulting in delayed flower development, were observed in transformants expressing CBM29-1-2 whereas such growth phenotypes were not observed for CBM2 $\underline{b}-1-2$ plants. Histological examination and electron microscopy
\end{abstract}

O. O. Obembe $\cdot$ E. Jacobsen $\cdot$ J. Timmers .

R. G. F. Visser · J.-P. Vincken $(\square)$

Graduate School Experimental Plant Sciences,

Laboratory of Plant Breeding, Wageningen University,

P.O. Box 386, 6700 AJ Wageningen, The Netherlands

e-mail: jean-paul.vincken@wur.nl

H. Gilbert

University of Newcastle upon Tyne,

Newcastle upon Tyne NE2 4HH, UK

A. W. Blake - J. P. Knox

Centre for Plant Sciences, University of Leeds,

Leeds LS2 9JT, UK

Present Address:

O. O. Obembe

Department of Biotechnology, Bells University of Technology,

P.M.B. 1015, Ota, Ogun State, Nigeria revealed layers of collapsed cortical cells in the stems of CBM29-1-2 plants whereas cellular deformation in the stem cortical cells of CBM2b-1-2 transformants was less severe. Altered cell expansion was also observed in most parts of the CBM29-1-2 stem whereas for the CBM2 $\underline{b}-1-2$ stem this was observed in the xylem cells only. The cellulose content of the transgenic plants was not altered. These results support the hypothesis that CBMs can modify cell wall structure leading to modulation of wall loosening and plant growth.

Keywords Carbohydrate-binding modules $\cdot$ Cell expansion - Cell wall modification - Cellulosehemicellulose networks - Plant growth and development . Promiscuous polysaccharide recognition

\section{Introduction}

Plant cell expansion depends on the interplay between internal driving forces and the controlled yielding of the cell wall. The ability of the wall to extend under this internal pressure is largely determined by wall loosening processes that modify the interaction of cellulose microfibrils with one another, and/or with hemicelluloses (Darley et al. 2001). Likewise, organ growth is brought about by differential rates of wall loosening, which causes differential tissue growth and, consequently, tissue tension within the organ (Peters and Tomos 1996, 2000). Thus, progressive modification of the cellulose-hemicellulose (mostly cellulosexyloglucan) networks is important in plant development.

In addition to their effect on plant growth, there are indications that interactions of hemicelluloses with cellulose can affect cellulose fibre properties. Using the Acetobacter model system, it was shown that cellulose-glucomannan 
and cellulose-galactomannan composites cause 57 and $32 \%$ loss of the crystallinity, respectively, of the native bacterial cellulose (Whitney et al. 1998). For cellulose-xyloglucan composites $29 \%$ loss of cellulose crystallinity was observed (Whitney et al. 1999). It was also shown that the composites were less stiff, leading to a dramatic reduction in mechanical strength, for example $80 \%$ reduction in composites with xyloglucan (Whitney et al. 1999, 2000). There are also reports which indicate that fibre properties depend on the side-chain substitution of the hemicelluloses. Studies on Arabidopsis thaliana mutants with mutations of the MUR2 and MUR3 genes, which encode xyloglucan-specific fucosyl and galactosyl transferases, respectively, revealed that the tensile strength of the fibre was enhanced by galactosylation of the xyloglucan (Pena et al. 2004; Ryden et al. 2003).

There are indications that the interactions between mannan-based polysaccharides and cellulose can affect the structural properties of the cell wall (Carpita et al. 2001; Hosoo et al. 2002). An immuno-localisation study of $A$. thaliana revealed that mannans were present in all thickened cell walls of stems and leaves, including those of the xylem parenchyma and epidermis (Handford et al. 2003). Mannan transglycosylase was recently identified and characterized as cell wall enzyme acting on mannan-based plant polysaccharides in primary cell walls of higher plants (Schroder et al. 2004). This body of evidence thus supports an emerging idea that mannan-based polysaccharides in cell walls may have a role analogous to that of xyloglucans, introducing flexibility and forming a growth-restraining network with cellulose.

Proteins, for example expansins, have been shown to be involved in modifying cellulose-hemicellulose interaction, thereby loosening the cell wall and ultimately regulating growth and developmental processes in which rearrangements in the cell wall are thought to be important (Cho and Cosgrove 2000; Choi et al. 2003; Pien et al. 2001; Zenoni et al. 2004). There is evidence that (heterologous) carbohydrate-binding modules (CBMs) could also affect these interactions (Levy et al. 2002; Shpigel et al. 1998), leading to altered structural morphology in transgenic plants (Kilburn et al. 2000; Quentin 2003; Shoseyov et al. 2001) or plant growth (Safra-Dassa et al. 2006). CBMs are noncatalytic polysaccharide-recognizing modules, appended to glycoside hydrolases, that often degrade water-insoluble polysaccharides and concentrate the enzymes on their target polysaccharides. CBMs are grouped into families based on amino acid sequence similarities; there are currently 47 families of CBMs in the database (http://www.afmb.cnrsmrs.fr/CAZY/). The biochemical characteristics of members of most of the CBM families have been established, including those that target non-cell wall polysaccharides such as starch and glycogen (reviewed by Boraston et al. 2004). Although most CBMs are linked to the catalytic modules of carbohydrate-active enzymes, some non-catalytic carbohydrate-binding proteins are not appended to any catalytic module. Examples of such proteins include putative CBMs of the A. thaliana former X8 family, now CBM43 (GenBank accession no. AL161503) (Henrissat et al., 2001), with olive pollen allergen Ole e 10 (GenBank accession no. AY082335) being the first characterized member of this family (Barral et al. 2005). Another example is the non-catalytic protein (NCP1) (CBM29; GenBank accession no. AY026754), which is a component of the anaerobic fungus Piromyces equi cellulase-hemicellulose complex (Freelove et al. 2001).

Because of the heterogeneous nature of the cell wall polysaccharides, several CBMs have evolved structures which enable them to recognize more than one wall polysaccharide (Boraston et al. 2004). Promiscuous recognition of carbohydrates by CBMs enables the associated enzyme (complex) to be more efficient in cell wall degradation. McCartney et al. (2006) showed that different xylan-specific CBM families can vary substantially in their binding to the cell wall. This indicates that the specificity of CBMs is so intricate that after expression in planta their effects on cell wall modification might be very local. To really affect wall architecture, it might be important to select CBMs that bind to different kinds of polysaccharide (promiscuous), so that the effect is not confined to one location or cell type. Most research activity relating to the potential use of CBMs for plant cell wall modification has been on cellulose-specific CBMs. In this investigation we have used different CBMs which not only recognise hemicellulose as opposed to CBM3 but are also to some extent promiscuous.

The CBM29 modules are an excellent model of promiscuity in protein-carbohydrate recognition. The modules bind soluble glucomannan, galactomannan, $\beta$-glucan, and hydroxyethylcellulose (HEC), and insoluble forms of cellulose and mannan (Charnock et al. 2002; Freelove et al. 2001). For all the ligands tested two appended copies of CBM29 (CBM29-1-2) had affinity substantially higher than the additive value of the individual modules. This indicates the two CBMs act in synergy to bind all their target ligands, with CBM29-2 having more affinity than CBM29-1. The tandem CBM29-1-2 was, additionally, able to interact with xyloglucan and different forms of xylans, whereas the single CBM had little affinity for these polysaccharides (Freelove et al. 2001; McCartney et al. 2004). An ex-situ labelling study has revealed that the tandem CBM29-1-2 modules bind strongly to the cell walls of the maize coleoptile sheath and the enclosed developing leaves (McCartney et al. 2004). This is indicative of the great abundance of their interacting ligands in the primary cell walls of grasses. It was therefore of interest to investigate the heterologous expression of these promiscuous CBMs in plants, and, more importantly, to compare their 
effects with those of less promiscuous CBMs, whose characteristics are described below.

Some ligand promiscuity is also observed for two consecutive family 2b CBMs (CBM2b-1 and CBM2b-2) from Cellulomonas fimi xylanase 11A. The tandem CBM2b-1-2 (note the underlining used throughout this report to distinguish it from CBM29-1-2) has very strong affinity for xylan and much lower affinity for insoluble acid-swollen cellulose (Bolam et al. 2001). It also has an 18 to 20-fold greater affinity for xylan than the individual modules.

We have expressed two CBM29 constructs, the tandem CBM29-1-2 and the single derivative CBM29-2, and the tandem CBM2b-1-2 construct in tobacco (all proteins targeted the cell wall) under the control of $35 \mathrm{~S}$ cauliflower mosaic virus (CaMV) promoter. It is shown that cell wall structural alterations in transgenic plants expressing CBM29-1-2 are more severe than those in CBM2 $-1-2$ transformants. Our results indicate that promiscuous carbohydrate binding modules can modulate cell wall structure and the development of transgenic tobacco plants.

\section{Materials and methods}

\section{Preparation of constructs}

Three constructs were prepared for expression in tobacco plants, one for single CBM29-2, one for tandem CBM29-12 , and one for tandem CBM2b-1-2. The CBM29 and CBM2b-1-2 constructs were prepared by amplifying their respective gene fragments from pET22b and pET28a, recombinant plasmid vectors used for cloning and expression in Escherichia coli (Bolam et al. 2001; Freelove et al. 2001). For the CBM29-1-2 fragment the polymerase chain reaction (PCR) was performed using primers that included BamHI and SmaI recognition sites (5'- cgggatccgttagt gctacttactctgttgtttat- $3^{\prime}$ and $5^{\prime}$-tccccgggecttttaatttattgggtca acgaaa-3'; the BamHI and SmaI sites, respectively, are underlined). The three bases highlighted in bold type are the stop codon. The amplified 914-base-pair fragment of the tandem CBM29-1-2 was digested with BamHI and SmaI (Invitrogen, The Netherlands) and cloned into a similarly digested binary vector pGreen7k (Hellens et al. 2000). Similarly, amplification of the single CBM29-2 fragment were performed using primers with the same restriction sites as for the tandem CBM29-1-2 (5'-cg ggatcccgtaatgtcagagccacttacactgt- $3^{\prime}$ and $5^{\prime}$-tccccoggcett ttaattattgggtcaacgaaa-3'; the BamHI and SmaI sites, respectively, are underlined). The amplified 559-base-pair fragment was digested with BamHI and SmaI (Invitrogen, The Netherlands) and cloned into pGreen $7 \mathrm{k}$ binary vector. Similarly, amplification and cloning of the 635-base-pair
CBM2b-1-2 fragment were performed using primers that included SmaI and EcoRI recognition sites at either end (5'-ccoggtgacacgggcggaggcggcggt- $3^{\prime}$ and 5'-ggaattctca gccegtggcgca-3'; the SmaI and EcoRI sites, respectively, are underlined). The cloning of the three fragments was inframe with fusion peptides of two sequences, which were cloned upstream in the binary vector. The first sequence codes for a tobacco transit peptide for transporting a cellular glycoprotein NTP303 across the plasma membrane into the cell wall (Wittink et al. 2000) whereas the second sequence encodes a hexahistidine tag. The sequence of the transit peptide was obtained as a product of annealing two oligonucleotide primers, TP1 (5'- agcttatgggaagtggtaaagtaa catttgtggctttgctactttgcetctccgtaggggtgatagctt- $\left.3^{\prime}\right)$ and TP2 (5' -ctagaagctatcaccctacggagaggcaaagtagcaaagccacaaatgtta ctttaccacttccata-3'). The underlined nucleotides produced overhangs of HindIII and XbaI, respectively. This fragment was then cloned into the HindIII and $X b a$ I cloning sites of the vector. Similarly, the sequence of the hexahistidine tag

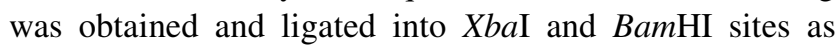
annealing product of His1 (5'-ctagaagaggatcgcatcaccatcac catcacg-3') and His2 (5' -gatccgtgatggtgatggtgatgcgatcctctt$3^{\prime}$ ), with the underlined nucleotides producing overhangs of $X b a \mathrm{I}$ and BamHI, respectively. The purpose of using the hexahistidine tag was to facilitate affinity purification of the CBM29 proteins. The control construct did not contain any of the CBMs, the transit peptide, or the hexahistidine epitope tag. All constructs were sequenced to verify their integrity.

Immunofluorescence detection of CBM29-1-2 and CBM2 $\underline{b}-1-2$ binding and microscopy

Wild-type tobacco plants (Nicotiana tabacum L.) were grown at $24^{\circ} \mathrm{C}$ under $16 \mathrm{~h}$ light and $8 \mathrm{~h}$ dark for 6-7 weeks. Regions of stem were excised and immediately fixed in PEM buffer (50 mmol L ${ }^{-1}$ PIPES (piperazine- $N, N^{\prime}$-bis[2ethanesulfonic acid]), $5 \mathrm{mmol} \mathrm{\textrm {L } ^ { - 1 }}$ EGTA (ethylene glycol $\operatorname{bis}\left(\beta\right.$-aminoethyl ether)- $N, N, N^{\prime} N^{\prime}$-tetraacetic acid), and $5 \mathrm{mmol} \mathrm{L}^{-1} \mathrm{MgSO}_{4}$, pH 6.9) containing 4\% paraformaldehyde. Samples were then dehydrated in an ethanol series $\left(30,50,70,90\right.$, and $97 \%$, each for $30 \mathrm{~min}$ at $4^{\circ} \mathrm{C}$, ethanol and wax $1: 1,37^{\circ} \mathrm{C}$, overnight) and embedded in Steedman's wax. Sections were cut to a thickness of $12 \mu \mathrm{m}$ and collected on polylysine-coated microscope slides (BDH Laboratory Supplies, Dorset, UK), de-waxed, and re-hydrated through a reverse ethanol series into phosphatebuffered saline (PBS) $(97 \%$ for $3 \times 10 \mathrm{~min}, 90 \%, 50 \%$ and water for $10 \mathrm{~min}$ each, and a final step of water $90 \mathrm{~min}$ ). For CBM labelling, sections were incubated in milk protein/PBS (to reduce any non-specific binding of proteins) and $5 \mu \mathrm{g} \mathrm{mL}^{-1} \mathrm{CBM} 29-1-2$ for $1.5 \mathrm{~h}$. Immunofluorescence detection of binding of CBM29-1-2 and CBM2b-1-2 to 
sections and microscopy were performed as described elsewhere (McCartney et al. 2004).

Tobacco transformation and regeneration

In vitro leaf explants of $N$. tabacum cv. Samsun NN were used for Agrobacterium tumefaciens-mediated transformation. Cloned binary vector pGreen $7 \mathrm{k}$ was co-transformed with the helper plasmid pSoup (Hellens et al. 2000) into A. tumefaciens strain LBA4404 by electroporation. This was plated out on LB-agar plates containing kanamycin $\left(100 \mu \mathrm{g} \mathrm{mL}^{-1}\right)$ and rifampicin $\left(30 \mu \mathrm{g} \mathrm{mL}^{-1}\right)$, and incubated for three days at $28^{\circ} \mathrm{C}$, to obtain single colonies. The integrity of the binary plasmids was tested by restriction analysis of plasmids isolated from A. tumefaciens cultures used for plant transformation. LB medium $(20 \mathrm{~mL})$ without selection was inoculated with a single colony and incubated overnight at $28^{\circ} \mathrm{C}$. The grown culture $(100 \mu \mathrm{L})$ was added to a Petri dish containing $10 \mathrm{~mL}$ Murashige-Skoog (MS30). Leaf explants, without major veins and edges, from young seedlings were transferred upside-down in to the MS30 medium. Agrobacterium infection was performed in the dark for 2 days at $24-25^{\circ} \mathrm{C}$. Two controls were used for the procedure, untransformed wild-type control and empty pGreen7k control without an insert. Leaf explants were washed in three changes of liquid washing medium of MS30 with $250 \mathrm{mg} \mathrm{L}^{-1}$ carbenicillin. The washed explants were transferred upside-up to an MS30-phytagel plate containing $0.1 \mathrm{mg} \mathrm{L}^{-1} \alpha$-naphthalene acetic acid (NAA), $1 \mathrm{mg} \mathrm{L}^{-1}$ 6-benzylaminopurine (BAP), $200 \mathrm{mg} \mathrm{L}^{-1}$ kanamycin and $250 \mathrm{mg} \mathrm{L}^{-1}$ carbenicillin, and incubated overnight in the dark at $28^{\circ} \mathrm{C}$. Plants were transferred to a growth chamber $\left(25^{\circ} \mathrm{C}\right)$, where they were gradually adapted to light and incubated for callus induction. After two weeks in culture, calli generated were transferred to shoot-inducing medium, MS20-phytagel, containing $0.2 \mathrm{mg} \mathrm{L}^{-1} \mathrm{NAA}, 2 \mathrm{mg} \mathrm{L}^{-1} \mathrm{BAP}, 200 \mathrm{mg} \mathrm{L}^{-1}$ kanamycin, and $250 \mathrm{mg} \mathrm{L}^{-1}$ carbenicillin. Well-formed shoots were harvested and transferred to root-inducing medium, MS15-phytagel plate containing $100 \mathrm{mg} \mathrm{L}^{-1}$ kanamycin, $250 \mathrm{mg} \mathrm{L}^{-1}$ carbenicillin, and $200 \mathrm{mg} \mathrm{L}^{-1}$ vancomycin. Transformed plantlets were transferred to the greenhouse to generate mature plants. Between fifteen to eighteen antibiotic-resistant tobacco transformants were generated for each of the three CBM transgenes.

RNA gel blot analysis of transgenic plants

Total RNA was isolated from 3 to $5 \mathrm{~g}$ transformed in-vitro shoots as described elsewhere (Kuipers et al. 1995). Aliquots of $20 \mu \mathrm{g}$ per lane were separated on a $1 \%$ formaldehyde agarose gel and blotted onto a Hybond-N nylon membrane (Amersham) by vacuum transfer in $0.4 \mathrm{~mol} \mathrm{~L}^{-1}$ sodium hydroxide. The membranes were hybridized with probes consisting of $60 \mathrm{ng}[\alpha 32 \mathrm{P}] \mathrm{dCTP}-$ labelled restricted fragments of CBM29-1-2, CBM29-2, or CBM2b-1-2. The radioactive labelled blots were exposed to X-OMAT $S$ and AR scientific imaging films (Kodak) at $-80^{\circ} \mathrm{C}$. The blots were re-hybridized, after stripping, with a 489 bp $[\alpha 32 \mathrm{P}] \mathrm{dCTP}-$ labelled fragment of a tobacco $18 \mathrm{~S}$ ribosomal RNA gene (GenBank accession no. AJ236016), as a control. The ribosomal probe was amplified from tobacco genomic DNA using oligonucleotides $5^{\prime}$-gaaactg cgaatggctcatt-3' and $5^{\prime}$-attaccgcggctgctggc- $3^{\prime}$ for PCR amplification.

\section{Protein extraction}

Protein extracts were prepared from transformed tobacco stems using $250 \mathrm{mmol} \mathrm{L}{ }^{-1}$ sodium phosphate buffer $(\mathrm{pH}$ 6.0), $0.5 \mathrm{~mol} \mathrm{~L}^{-1} \mathrm{NaCl}, 5 \mathrm{mmol} \mathrm{L}{ }^{-1}$ EDTA, 0.1\% (v/v) Tween 20, protease inhibitor (Complete, Roche), $37.5 \mathrm{mg} \mathrm{mL}^{-1}$ PVPP (adapted from Vincken et al. 1998). The protein samples were incubated for $2 \mathrm{~h}$ at $4^{\circ} \mathrm{C}$ with gentle shaking. After incubation the samples were centrifuged at $4,500 \mathrm{~g}$ and $4^{\circ} \mathrm{C}$ for $20 \mathrm{~min}$. The supernatant containing the soluble protein fraction was then collected. The protein samples were then concentrated with Centricon Plus-20 devices (Millipore) according to supplier's procedure. Protein concentrations were determined with an ESL protein assay (Roche) using BSA as standard.

Incubation of RGS.(HIS) $)_{6}$-tagged size marker in protein extract of wild-type tobacco

Protein extracts were prepared from wild-type tobacco as described above, either lacking or supplemented with $5 \mathrm{mmol} \mathrm{L}{ }^{-1}$ EDTA and protease inhibitor (Complete, Roche). RGS.(HIS $)_{6}$-tagged size marker was incubated with the protein extracts as follows. A batch of RGS.(HIS) ${ }_{6}$-tagged size marker (Qiagen) was dissolved in $100 \mu \mathrm{L} 50 \mathrm{mmol} \mathrm{L}^{-1}$ Tris, pH 7.5, such that the final concentration of the individual proteins varied from 50 to $75 \mathrm{ng} \mu \mathrm{L}^{-1}$. The epitope-tagged size marker $(2 \mu \mathrm{L})$ was added to $18 \mu \mathrm{L}$ tobacco extracts. The mixtures were incubated at room temperature for approximately $15 \mathrm{~h}$. As a control, RGS.(HIS) ${ }_{6}$-tagged size marker was incubated in $50 \mathrm{mmol} \mathrm{L}{ }^{-1}$ Tris, pH 7.5.

Western blot analysis

The protein samples were separated with SDS-PAGE on 12\% SDS-polyacrylamide gels (Mini-Protean II apparatus, Bio-Rad). The separated proteins were electroblotted on to 
a nitrocellulose membrane in $192 \mathrm{mmol} \mathrm{L}^{-1}$ glycine, $25 \mathrm{mmol} \mathrm{L}{ }^{-1}$ Tris base, $0.1 \%(w / v)$ SDS, $20 \%(v / v)$ ethanol, $\mathrm{pH}$ 8.3. Blocking against non-specific binding was performed for $2 \mathrm{~h}$ with $3 \%(w / v)$ BSA (Sigma) in TBS (10 $\mathrm{mmol} \mathrm{L}^{-1}$ Tris, $150 \mathrm{mmol} \mathrm{L}^{-1} \mathrm{NaCl}, \mathrm{pH}$ 7.5). The membrane was then incubated with a 1:1000 dilution of the primary anti-RGS.HIS antibody (Qiagen) in TBS solution containing $3 \%(w / v)$ BSA for $2 \mathrm{~h}$. The membrane was washed twice in TBS-TT buffer $\left(20 \mathrm{mmol} \mathrm{L}^{-1}\right.$ Tris base, $500 \mathrm{mmol} \mathrm{L}^{-1} \mathrm{NaCl}, \mathrm{pH} 7.5,0.05 \%$ ( $v / v$ ) Tween 20, 0.2\% $(v / v)$ Triton X-100), and once in TBS buffer, for $10 \mathrm{~min}$ each. The membrane was then washed with 1:2000 dilution horseradish peroxidase (HRP) conjugated sheep anti-mouse antibody (Amersham) in TBS buffer containing $10 \%(w / v)$ non-fat dried milk. The membrane was washed in TBS-TT buffer four times, $10 \mathrm{~min}$ each, and subsequently submerged in Supersignal ULTRA substrate working solution (Pierce), which is a mixture of equal parts of Ultra luminol/ enhancer solution and Ultra stable peroxide solution. Finally, the membrane was exposed to X-OMAT S Scientific Imaging films (Kodak) at room temperature.

Monitoring the growth of the transformed plants

To monitor growth of the transformed plants with time, three replicates per line were grown in the greenhouse. The transformants were grown in two series, the CBM29s and CBM2b-1-2 series, with each series having its separate controls. Height measurements of the stems were taken weekly for nine weeks, starting from week two after transplant. The height measurements of six individual high expressers, each from transgenic lines containing CBM291-2 and CBM29-2 constructs, six transformed controls, and six untransformed controls from week 3 to week 9 were subjected to one-way analysis of variance (ANOVA), using an $\alpha$ of 0.05 . To test whether the differential stem elongation was significant, a Fisher's unprotected least significant difference test was used. The null hypothesis of no difference between plant heights was rejected at an error of 0.05 .

\section{Light microscopy}

Three individual plants per transgenic tobacco line and three wild-type plants, as control, were used for microscopic examination. Three transgenic lines were used per construct (two high expressers and one low expresser). Stem samples were taken from the second internode from the top of the plant. Stem sections $1 \mathrm{~mm}$-thick were fixed in $3 \%$ glutardialdehyde (Merck) and 3\% paraformaldehyde (Merck) in $0.1 \mathrm{~mol} \mathrm{~L}^{-1}$ phosphate buffer containing $0.1 \%$ Triton $\mathrm{X}$ 100 for $2 \mathrm{~h}$. The samples were then washed and dehydrated in an ethanol series. After dehydration they were embedded in Technovit 7100 resin (USA) (Kuroiwa et al. 1990). Sections $4 \mu \mathrm{m}$-thick were stained with $0.1 \%$ toluidine blue (Aldrich) and examined under a bright field microscope.

Cryo-scanning electron microscopy and quantification of cell size and cell wall diameter

One high expresser from each of the CBM29s and CBM2b1-2 transgenic lines and one individual plant each from their respective controls were used for cryo-SEM examination. The plants that were analysed were chosen on the basis of the results obtained from the extensive light microscopic analysis that showed a consistent pattern of alterations in high-expressing transgenic plants. Stem sampling was the same as for the light microscopy. Stem samples $6 \mathrm{~mm}$ thick were mounted in a brass cylindrical sample holder with TBS tissue freezing medium (EMS, Washington, PA, USA). The frozen samples were placed in a sample holder in a cryo-ultra microtome (Reichert Ultracut E/FC4D) and cut at a specimen temperature of $100^{\circ} \mathrm{C}$. These samples were first planed with a glass knife, after which the surface was planed with a diamond knife (Histo no trough, $8 \mathrm{~mm}$ $45^{\circ} \mathrm{C}$; Drukker International, The Netherlands). After planing, the samples were placed in a dedicated cryopreparation chamber (CT $1500 \mathrm{HF}$, Oxford instruments, UK). All the samples in the cryo-preparation chamber were freeze dried for $3 \mathrm{~min}$ at $-90^{\circ} \mathrm{C}$ and $8 \times 10^{-4} \mathrm{~Pa}$, and subsequently sputtered with a $10-\mathrm{nm}$ layer of $\mathrm{Pt}$. The samples were cryo-transferred into the field emission scanning microscope (Jeol 6300F, Japan) on the sample stage at $-190^{\circ} \mathrm{C}$. All images were recorded digitally (Orion, 6 E.L.I. sprl, Belgium) at a scan rate of $100 \mathrm{~s}$ (full frame) at the size of $2,528 \times 2,030,8$ bit. The images were optimized and resized for publication by use of Adobe Photoshop CS.

To quantify the micrographic images, files were opened with Image $\mathbf{J}$ software developed at the National Institute of Health, USA (http://www.rsb.info.nih.gov/ij/). The surface area of three hundred cortical and xylem cells was measured as shown by the insets in Figs. $7 \mathrm{a}$ and $7 \mathrm{~b}$. One hundred cells per field of view were measured in three replicates. Similarly, cell wall thickness of 150 cells was quantified as shown by the inset in Fig. 7c. Fifty cells per field of view were measured in three replicates. Standard deviations of three measurements were determined.

Isolation of cell wall material and analysis of the cellulose content

Stem samples from one high expresser of the CBM29 and CBM2b-1-2 series, one pGreen7k vector control, and one wild-type control plant were ground to a fine powder in 
liquid nitrogen. For each isolation, $1 \mathrm{~g}$ of this stem material was extracted in a $50 \mathrm{mmol} \mathrm{L}{ }^{-1}$ Tris[HCl], $\mathrm{pH} 7.2$ solution containing $1 \% \mathrm{SDS}$, for $3 \mathrm{~h}$ at room temperature (RT) with continuous shaking. The cell wall material CWM was spun down by centrifugation at 13,000 rpm for $15 \mathrm{~min}$. Subsequently, the residue was washed with water, ethanol, and acetone, then air-dried. The different cell wall materials (10 mg) were hydrolysed in $1 \mathrm{~mL} 2 \mathrm{~mol} \mathrm{~L}^{-1}$ TFA. The TFA-insoluble cellulose was spun down at 13,000 rpm for $15 \mathrm{~min}$, and the pellet was suspended in $67 \%$ sulfuric acid. The suspension was heated and diluted appropriately to determine the cellulose content colorimetrically, using anthrone as colouring agent (Updegraff 1969). The acid hydrolysis was performed in quadruplicate.

\section{Results}

Expression of bacterial CBM29 and CBM2b-1-2 genes in tobacco

To detect expression of the introduced CBM genes in the tobacco plant, we performed Northern blot analysis with total RNA. Figure 1 shows representatives of three classes of transcript expression (high, low, and none) of the three CBM modules as revealed by the Northern analysis. Ten of the CBM29-1-2 plants were classified as high expressers, five as low expressers, and two as none expressers. For the CBM29-2 plants, ten lines were classified as high expressers, seven as low expressers, and two as none expressers (note that none expressers may include plants with very low RNA expression, which could not be detected). For the CBM2b-1-2 plants, six each were classified

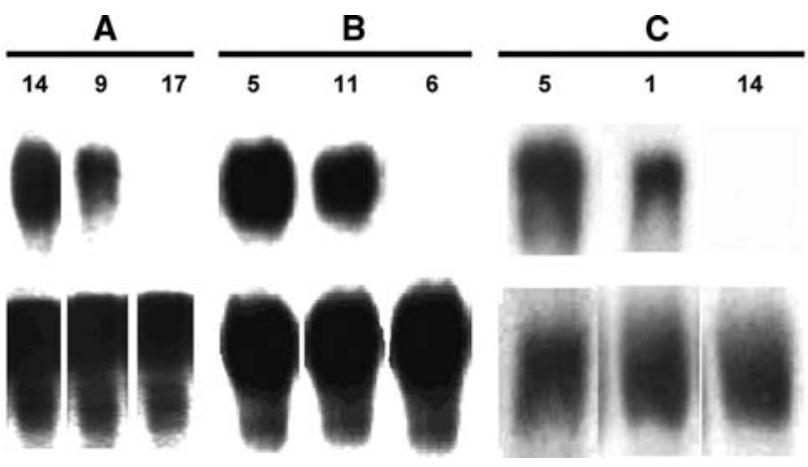

Fig. 1 Transcript analysis of CBM29 and CBM2b-1-2 genes in transgenic tobacco leaves. A differential transcript expression pattern is shown in the upper panel with the representative of each class in the three transgenic lines CBM29-2 (a), CBM29-1-2 (b) and CBM2b1-2 (c). Line 14 in a line 5 in both $\mathbf{b}$ and $\mathbf{c}$, represent high expressers. Lines 9,11 and 1 represent low expressers. Line 17 in a, line 6 in b and line 14 in $\mathbf{c}$ represent none expressers. The lower panel shows RNA blots for the 18S ribosomal RNA internal control for each of the series as high and low expressers whereas four plants were classified as none expressers. Preliminary attempts at purifying CBM proteins using affinity purification with the hexahistidine tag were not successful (data not shown). Similarly, Western detection of a hexahistidine epitopetagged fungal elicitor protein ECP2 that was infiltrated into the apoplast of leaves did not succeed in the tomato plants but succeeded in Arabidopsis thaliana (van Esse et al. 2006). The results indicated that the histidine tag was cleaved in the tomato plants but not in A. thaliana. These observations have since led to the idea that the hexahistidine epitope tags have cleavage sites recognized by proteases, which are specific for the cell walls of the solanaceous species.

We corroborated this notion by incubating a protein ladder, consisting of five different proteins of known sizes, each containing an N-terminal RGS.(HIS) ${ }_{6}$-tag, in protein extracts of wild-type tobacco (Compier 2005). The tagged proteins of the size marker that were incubated in tobacco extract without EDTA and protease inhibitor were not detectable on a Western blot whereas the markers incubated in extract supplemented with EDTA and protease inhibitor were detected. This suggested that extracts from tobacco contained proteases that could remove the hexahistidine epitope tag.

Because grinding of the plant material and protein extraction were performed at $4^{\circ} \mathrm{C}$, and the protein extraction buffer contained EDTA and protease inhibitor, removal of the RGS.(HIS) ${ }_{6}$-tag from the fusion proteins had probably occurred already in planta, most probably extracellularly. It should be noted that with the presence of the NTP303 signal peptide, the fusion proteins would be secreted into the apoplast. Cleavage of the RGS.(HIS) ${ }_{6}$-tag was, therefore, likely to occur after translocation into the extracellular space.

\section{CBM29-1-2 and CBM2b-1-2 have different}

binding patterns in the stem

Immunofluorescence detection of CBM29-1-2 and CBM2b-1-2 binding to stems of the wild-type tobacco plant was performed order to determine, a priori, the particular tissues of the stem where the introduced CBM29-12 module would bind. Indirect immunofluorescence micrographs (Fig. 2) revealed that CBM2b-1-2 binding is restricted to the secondary cell walls of stem vascular tissue-xylem cells and phloem fibres (Fig. 2a)-whereas CBM29-1-2 indiscriminately binds to every tissue of the stem, from the epidermis through the cortex and the vascular tissue to the pith parenchyma in the innermost part (Fig. 2b). In the control (no CBM) weak autofluorescence was observed in the xylem vessel cell walls (Fig. 2c). This ex-situ evidence for unselective binding of the CBM29-1-2 
Fig. 2 Micrographs, obtained by indirect immunofluorescence microscopy, showing binding of CBM2b-1-2 (a), CBM29-1-2 (b), and control (no CBM) (c) to transverse sections of wild-type tobacco stem. The CBM29-1-2 binds indiscriminately to every tissue of the stem, from the epidermis through the cortex and the vascular tissue to the pith parenchyma in the innermost part whereas CBM2b-1-2 binding is restricted to the vascular tissues. $c t$ cortical parenchyma, $x y$ xylem cells, ph pith. Arrow head indicates the epidermis. Arrow indicates the phloem fibres. Scale bar $=100 \mu \mathrm{m}$
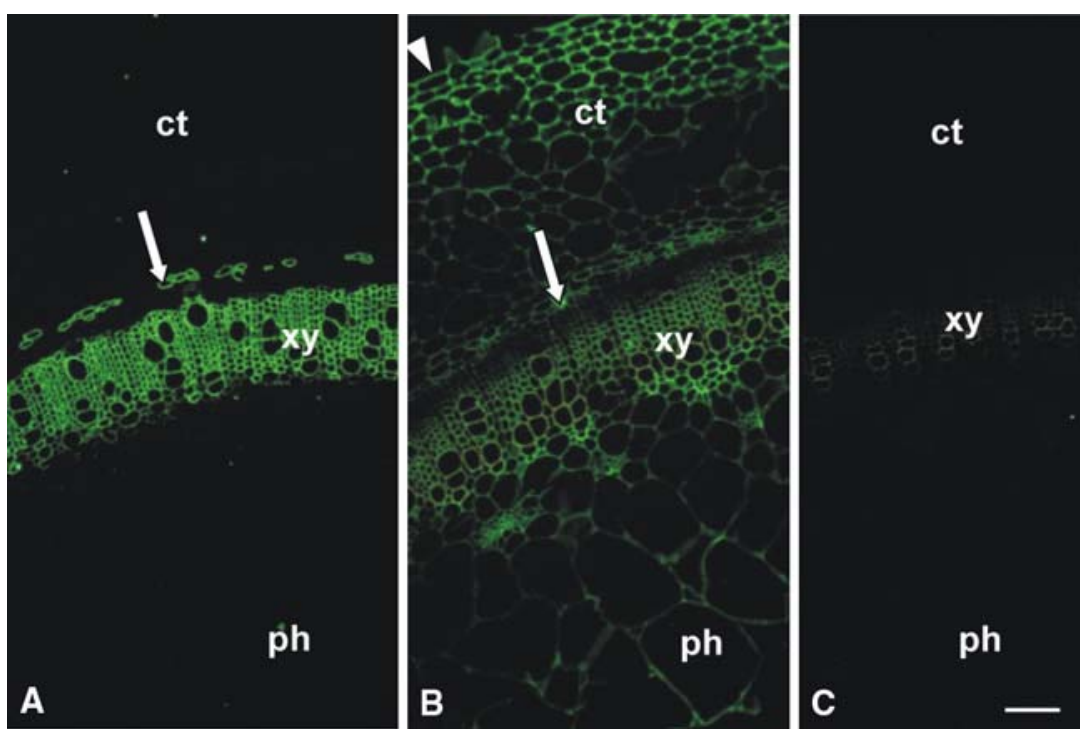

to both the primary and the secondary cell walls of the mature stem of the tobacco plant thus complements earlier evidence for its binding to a predominantly primary-walled maize coleoptile (McCartney et al. 2004). It should also be noted that tobacco is a dicotyledonous plant whereas maize is monocotyledonous, and that there are many differences between the polysaccharide composition of the walls of these species. Both results thus confirm the binding promiscuity of the tandem CBM29-1-2, as previously characterized (Charnock et al. 2002; Freelove et al. 2001). We also conclude that the CBM2 $-1-2$ ligands are present in the vascular tissue of the stem.

Reduced stem elongation and prolonged juvenility are observed for CBM29-1-2 transformants

An indication of reduced stem elongation in the transgenic plants expressing the tandem CBM29-1-2 was first apparent after the third week of transfer to the greenhouse. The different stem elongation of the tandem CBM29-1-2expressing plants and the control plants became significant $(P<0.05)$ at weeks seven and eight, when other plants had reached their final height (Table 1, Fig. 3). The tandem CBM29-1-2-expressing plants continued to increase in height until the eleventh week, however, when they reached their final height, an average of $58 \mathrm{~cm}$. There was, as a result, no significant difference between the heights of the tandem CBM29-1-2 lines at maturity and the heights of the single CBM29-2 lines, the pGreen vector control, and the wild-type control plants. There was no significant difference, at any time, between stem elongation of transgenic plants expressing CBM29-2 and the control plants.

In addition to reduced stem elongation it was also observed that flower development was delayed in the tandem CBM29-1-2-expressing plants. We observed that at week eight, when most plants had already flowered (Fig. 3) and set fruit (data not shown), the tandem CBM29-1-2expressing plants were just developing flower buds (Fig. 3). The flower buds eventually developed into normal flowers and also set fruits. Most plants, except the CBM291-2 plants, had also lost many leaves, because of faster ageing (Fig. 3).

There was no morphological or developmental change in the transgenic plants expressing the tandem CBM2 $\underline{b}-1-2$

Table 1 Plant height (cm) of transgenic lines CBM 29-1-2, CBM 29-2, empty pGreen7k control, and wild-type control

\begin{tabular}{|c|c|c|c|c|c|c|c|}
\hline \multirow[t]{2}{*}{ Plant line } & \multicolumn{7}{|c|}{ Weeks after transplant } \\
\hline & 3 & 4 & 5 & 6 & 7 & 8 & 9 \\
\hline CBM29-1-2 & $9.5 \pm 1.3$ & $16.1 \pm 2.2$ & $27.0 \pm 3.8$ & $37.7 \pm 5.5$ & $43.1 \pm 5.3^{\mathrm{a}}$ & $50.5 \pm 5.4^{\mathrm{a}}$ & $56.6+6.7$ \\
\hline CBM29-2 & $9.3 \pm 1.3$ & $16.9 \pm 1.9$ & $27.5 \pm 3.2$ & $40.9 \pm 5.0$ & $50.7 \pm 4.1$ & $57.8 \pm 4.1$ & $63.8+4.7$ \\
\hline PGreen7k & $9.5 \pm 1.6$ & $17.3 \pm 2.3$ & $30.1 \pm 3.8$ & $44.6 \pm 5.2$ & $57.6 \pm 7.1$ & $63.1 \pm 5.8$ & $65.4+5.6$ \\
\hline WT Ctrl & $9.7 \pm 1.3$ & $17.1 \pm 2.3$ & $31.5 \pm 3.7$ & $50.6 \pm 7.3$ & $63.6 \pm 7.1$ & $68.4 \pm 5.5$ & $68.8+5.6$ \\
\hline
\end{tabular}

The values are means and standard deviations for six transgenic lines (high expressers) and six control plants. Each line has three individual plants (three replicates)

${ }^{a}$ Plant height significantly different from that of controls 
Fig. 3 Reduced stem

elongation in time, and delayed development of CBM 29-1-2 transgenic tobacco plants. The picture was taken at week eight

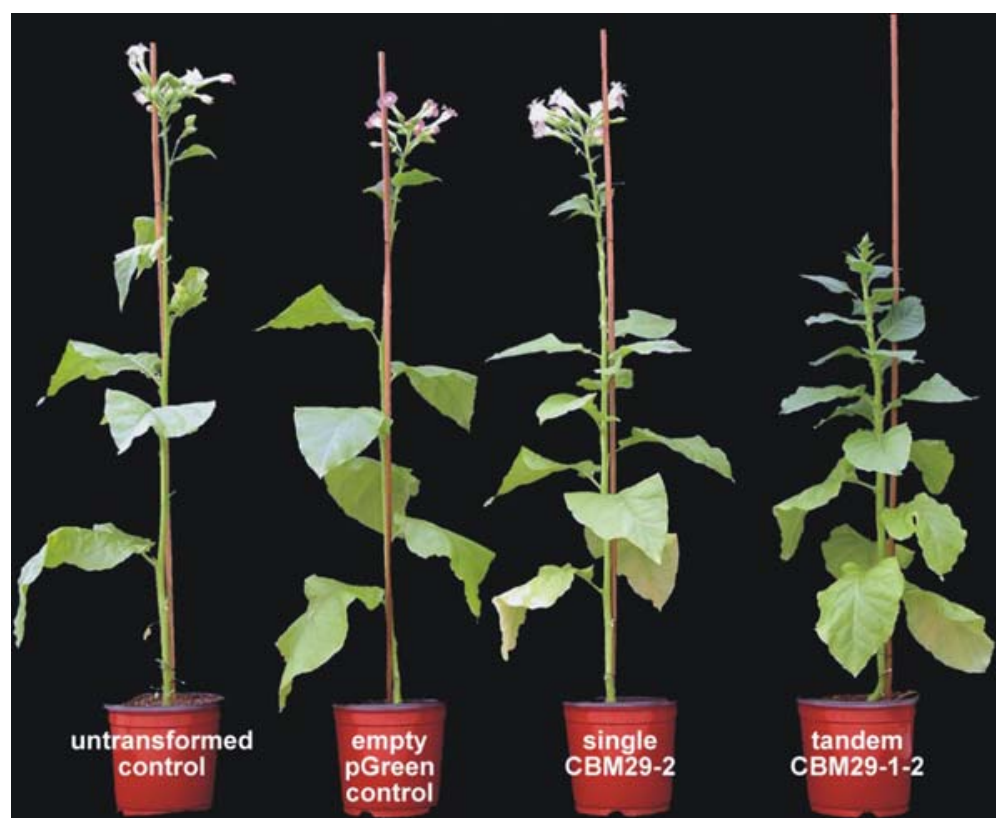

gene compared with the pGreen $7 \mathrm{k}$ vector control. The average plant height of the tandem CBM2 $\underline{b}-1-2$ series at maturity was $71 \mathrm{~cm}$, which was comparable with the $75 \mathrm{~cm}$ average height for their pGreen $7 \mathrm{k}$ vector control plants. We also did not observe a particular trend in plant development with regard to stem elongation, leaf abscission, or flower formation.

Cellular alterations are observed in transgenic plants

The cellular basis for the CBM29-1-2 plant phenotypes was examined by histological examination of the transgenic tobacco stems. The examination revealed a prominent layer of collapsed cells in the cortex of the stems of the tandem CBM29-1-2-expressing plants (Figs. 4a, 5a). We also observed that this morphological alteration is consistently more severe in the high expressers than in the low expressers. This alteration was also observed in the high expressers of the single CBM29-2, although it was much less severe (Fig. 4c). For the CBM2b-1-2 stems, irregularly shaped cells were observed in the cortex of the high expressers (Fig. 5c). The micrographs of both the empty vector control and untransformed wild-type control looked the same; hence the pGreen $7 \mathrm{k}$ micrograph was taken to represent the controls (Fig. 4b). Altered cell enlargement across the tissues in the CBM29s-expressing stems was also observed. This was particularly true for the tandem CBM29-1-2-expressing plants (compare, for example, Figs. 5a and $5 \mathrm{~d}$ with $5 \mathrm{~b} / \mathrm{c}$ and $5 \mathrm{e} / \mathrm{f}$, respectively). The altered cell size phenotype is
Fig. 4 Cross sections of transgenic and control stems, showing collapsed cortical cells and enlarged cortical and xylem cells of the CBM29-1-2 stems. Sections of CBM29-1-2

(a), empty Pgreen 7k control (b), CBM29-2 stem (c), and CBM2b-1-2 (d) were stained with toluidine blue. The boxed area indicates tissues shown with higher magnification in Fig. 5. ep epidermis, $c t$ cortex, $x y$ xylem, $p h$ pith
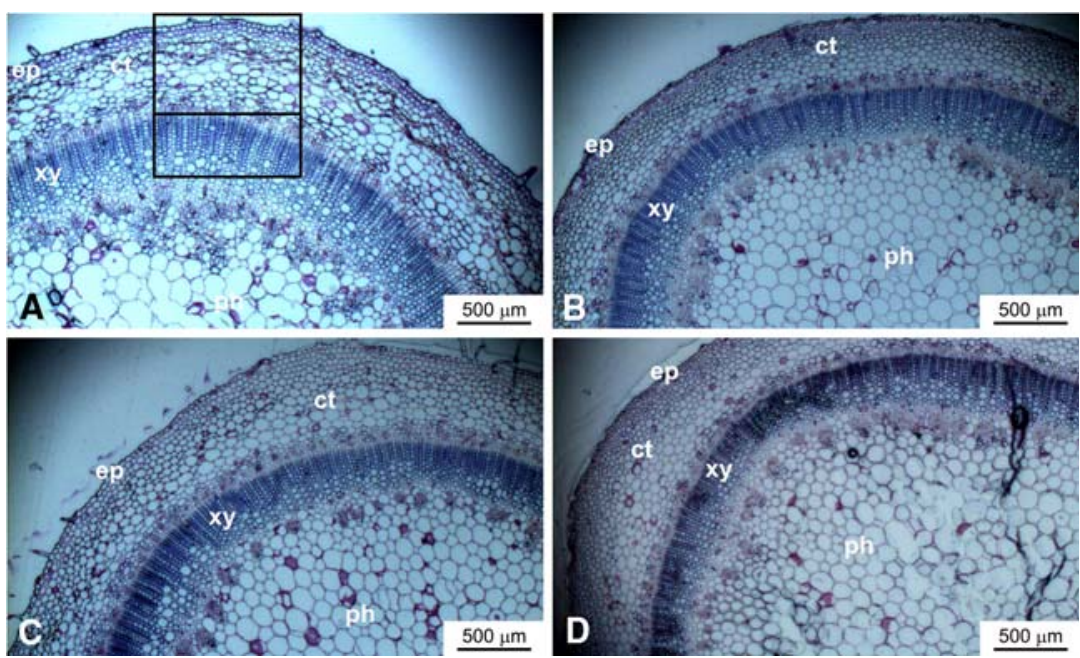
Fig. 5 Magnification $(10 \times)$ of cross sections of CBM29-1-2 stem $(\mathbf{a}, \mathbf{d})$, control stem $(\mathbf{b}, \mathbf{e})$, and CBM2b-1-2 stem (c, f). Micrographs show collapsed cortical cells (a), enlarged cortical and xylem cells of the CBM29-1-2 stems (a, d), and irregularly shaped stem cortical cells of the CBM2 $\underline{b}-1-2$ stems (c). Asterisks indicate irregular cortical cells in the CBM2b-1-2 transformants; in the $\mathrm{CBM} 29$ 1-2 transformants these cells are more apparent and are not highlighted. $e p$ epidermis, $c t$ cortex, $x y$ xylem, $p f$ phloem fibre
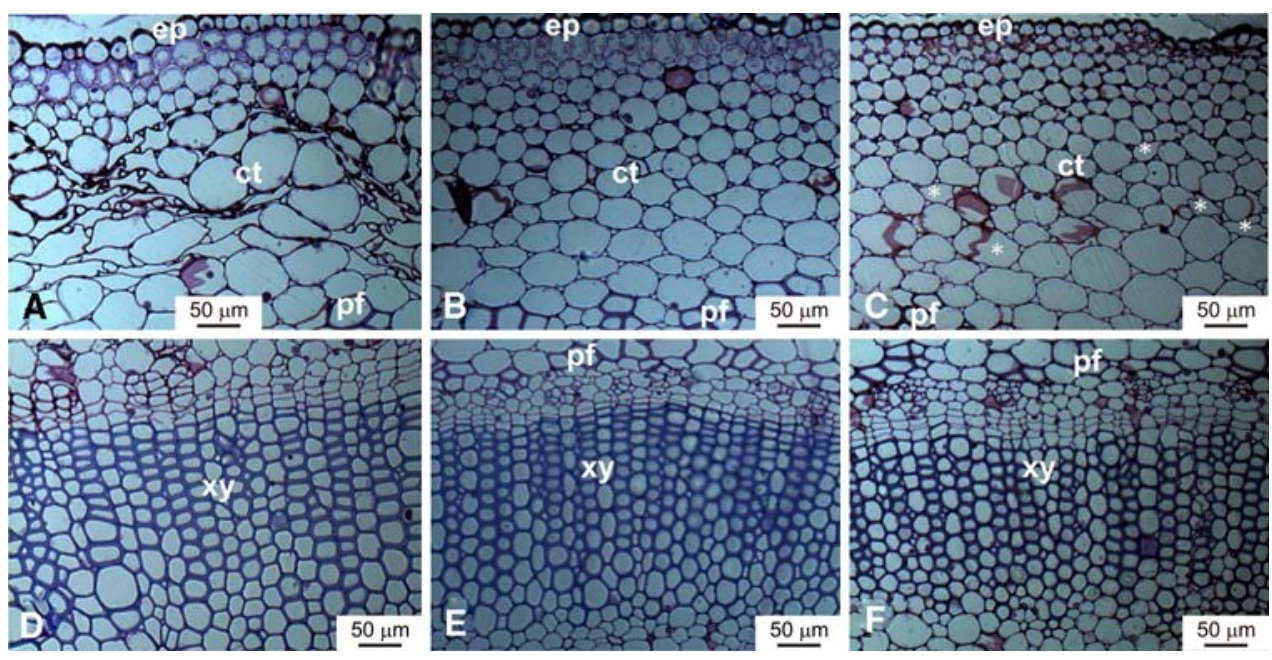

widespread in the high and low CBM29-1-2-expressing plants. This is not observed, however, in the single CBM29-2-expressing stems, in which only the high expressers had noticeably larger cells in the epidermal, cortex, and xylem tissues than those of the controls. Similarly, there was an indication of larger xylem cells in the outermost layer of the CBM2 b-1-2 stems than in controls (compare Figs. 5e and 5f). There was, however, no clear indication of altered enlargement of the stem pith parenchyma cells of the transgenic plants.

\section{Cryo-scanning electron microscopy (cryo-SEM) of tobacco stems}

To establish that the transgenic stems indeed had larger cells than those of the controls we made cryo-SEM examinations of stem samples. Figure 6a shows the collapsed and enlarged cells of the cortex in the sections of transgenic line 5 of CBM29-1-2, as previously observed by light microscopic examination. The cortical cells of the control plant were smaller and the collapsed phenotype was not apparent (Fig. 6b). The micrographs also showed that xylem cells were indeed larger in the CBM29s-expressing stems than in the controls (compare transgenic line 5, Fig. 6c and the empty vector control, Fig. 6d). The micrographs also indicated that the cell walls of the xylem cells were thinner in the CBM29s-expressing stems (Fig. 6c) than in stems of controls (Fig. 6d). Similar micrographs were obtained for the CBM2b-1-2 series, which confirmed that the radial surface area and cell wall diameter of their stem xylem cells were larger and thinner, respectively, than those of the controls (data not shown). These notable observations were later substantiated by quantification. Figure 7 a shows that almost $50 \%$ and $40 \%$ of the stem cortical cells of the wild-type and pGreen $7 \mathrm{k}$ control plants, respectively, were grouped in the small class $\left(50-100 \mu \mathrm{m}^{2}\right)$, whereas fewer than $20 \%$ of the stem cortical cells of the CBM29s-expressing plants were grouped in the small class. An opposite trend was observed in the large class $\left(150-200 \mu^{2}\right)$-fewer than $20 \%$ of the cortical cells of the two control stems were grouped compared with more than 30 and $40 \%$ of the stems expressing the single CBM29-2 and the tandem CBM29-1-2, respectively. We thus infer that the cortical cells of the CBM292-expressing stems are larger than those of the control stems. Similar quantitative data were obtained from the xylem cells depicted in Fig. 7b, which shows that only the xylem cells of the CBM29-1-2-expressing stems are larger than those of the control stems. There was no difference between the size of the xylem cells of the single CBM29-2 stems and those of the controls. Similarly, we quantified the thickness of the cell walls of the xylem cells of the CBM29s-expressing stems and the pGreen7k control stems as presented in Fig. 7c. Approximately $45 \%$ of the cell walls of the xylem cells of the CBM29-1-2-expressing stem were grouped in the thin class $(1.2-2 \mu \mathrm{m})$ whereas fewer than $10 \%$ of the stem xylem cell walls of the single CBM29-2, the pGreen7k control, and the wild-type control plants were grouped in this class. More than $60 \%$ of the xylem cell walls of the two control stems were grouped in the thick class $(2.8-3.6 \mu \mathrm{m})$ whereas approximately 22 and $0 \%$ of the stem xylem cell walls of the single CBM29-2 and the tandem CBM29-1-2, respectively, were grouped in this class. We can also infer from this result that the thickness of the cell walls of the xylem cells of the CBM29-2-expressing stems (particularly of the tandem CBM29-1-2) are thinner than those of the pGreen7k and the wild-type control stems.

A similar trend was observed for the xylem cells of the CBM2b-1-2 stems, which were larger than those of the pGreen $7 \mathrm{k}$ control plants (data not shown). Similarly, the cell walls of the xylem cells of the CBM2b-1-2-expressing stems were thinner than those of the $\mathrm{p}$ Green $7 \mathrm{k}$ control stems (data not shown). 
Fig. 6 Scanning electron micrographs of transgenic tobacco stems to show details of larger cells and thinner cell walls of the CBM 29-1-2 stems compared with the pGreen $7 \mathrm{k}$ control. CBM29-1-2 (a) and (c), and empty pGreen $7 \mathrm{k}$ control (b) and (d). $\mathbf{a}$ and $\mathbf{b}$ show the cortex tissue whereas $\mathbf{c}$ and $\mathbf{d}$ show the xylem tissue. $p f$ phloem fibre, $x y$ xylem, ct cortex. Arrow heads indicate collapsed layer of cortical cells
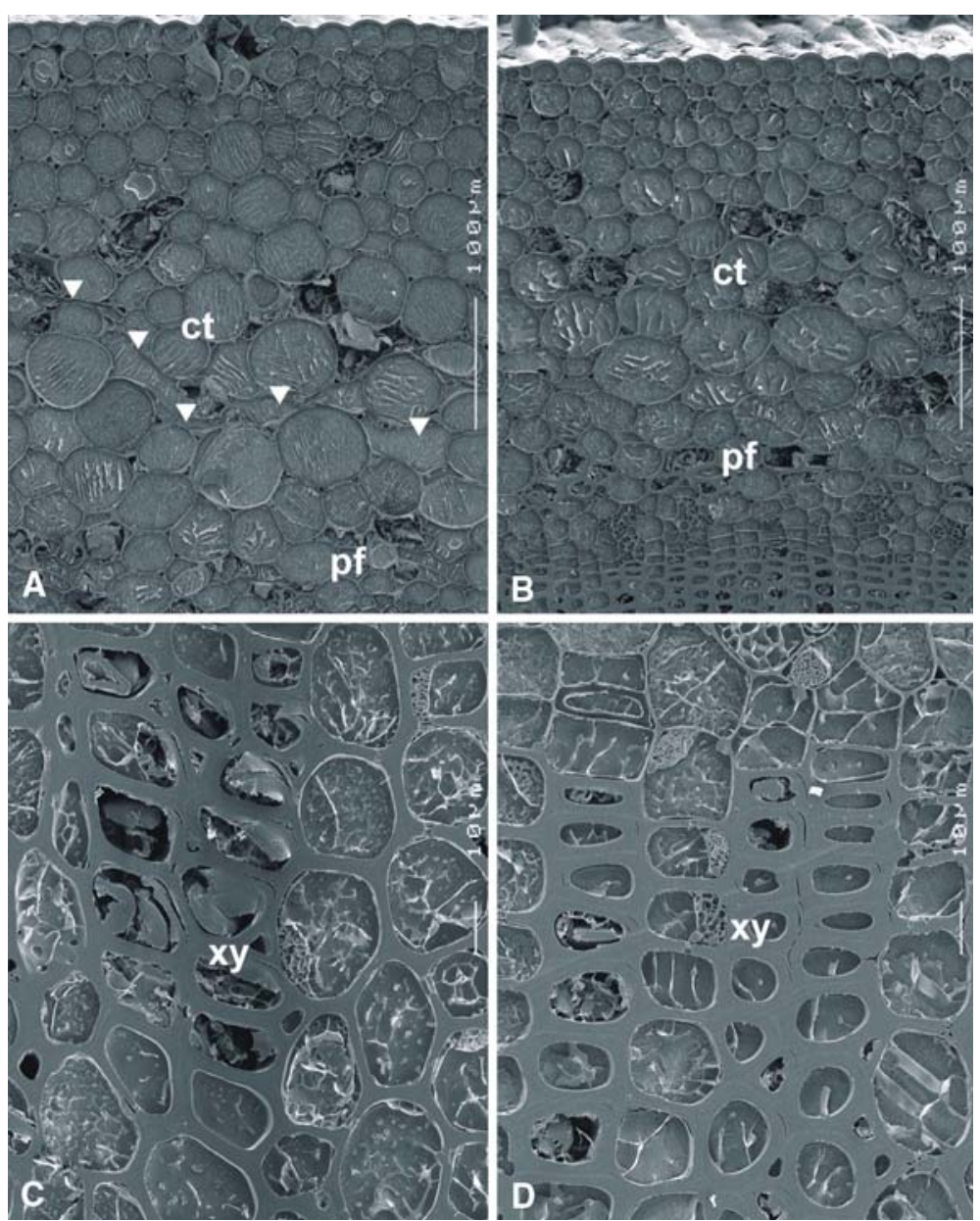

\section{Analysis of cellulose content}

A colorimetric assay was performed on samples of crystalline cellulose obtained from four separate acid hydrolyses to determine the cellulose content in the stem cell walls of the CBM29s and CBM2b-1-2 transformants and the control plants. There were no substantial differences between levels of cellulose in the stem cell walls of the transgenic tobacco lines expressing the single CBM29-2, the tandem CBM29-1-2, the tandem CBM2b-1-2, the empty vector control, and the wild-type control plants (data not shown). Hence, it can be concluded that use of these CBMs for cell wall modification did not interfere with the extent of cellulose biosynthesis.

\section{Discussion}

It has been suggested that networks of plant cell wall polysaccharides can affect the properties of cellulose fibres. We hypothesized that expression of promiscuous CBMs in tobacco plants might lead to modification of these networks, although they might also affect plant development in more general terms. In this study, expression of two promiscuous Piromyces CBM29-containing proteins was targeted at tobacco cell walls to provide baseline information on the possibility of using CBMs for in-planta modification of the properties of cellulose fibre for industrial applications. In parallel, we also targeted the expression of the less promiscuous tandem CBM2 $\underline{b}-1-2$ protein of the $C$. fimi xylanase $11 \mathrm{~A}$, with a view to comparing its effect with that of the more promiscuous CBM29-1-2.

Our results reveal that the tandem CBM29-1-2 modified the tobacco cell wall structure with consequent altered cellular and organ morphology. The tandem CBM29-1-2 modules had more effect than the single CBM29-2. Expression of the tandem CBM29-1-2 modules in the tobacco cell wall affected plant development, as reflected by reduced stem elongation rate, enlarged xylem, and collapsed cortical cells. The stem phenotype of the CBM29-1-2-expressing plants was more of delayed development of the whole plant rather than mere elongation defects of the stem. We suggest that the delayed development (prolonged juvenility) was as a result of 

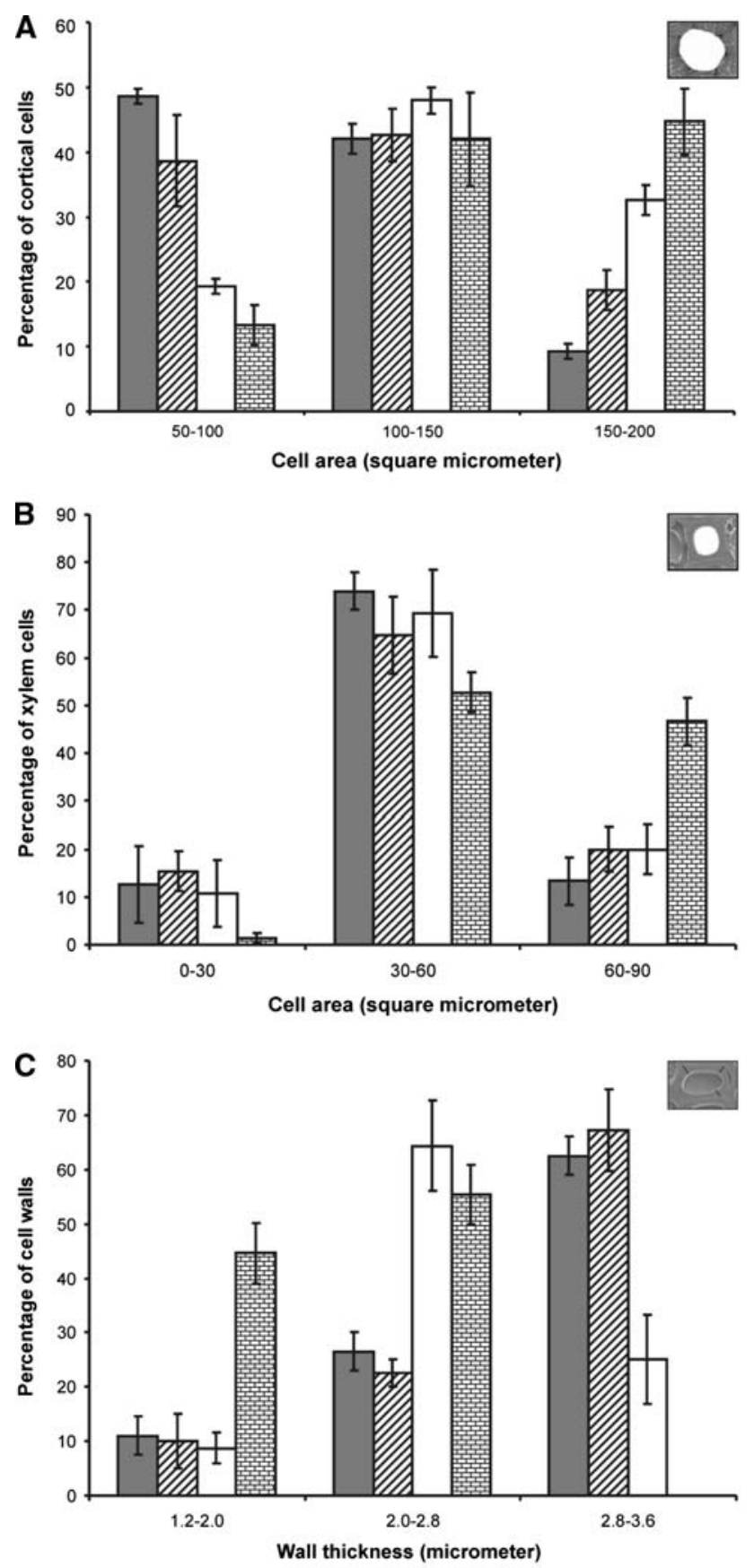

Fig. 7 Cell size distribution in the cortex (a), cell size distribution in the xylem (b), and cell wall thickness of xylem cells (c) in the stems of transgenic and the wild-type tobacco plants. Insets show how the surface area and wall thickness measurements were taken. Surface areas of 300 cells were measured, 100 cells per field of view. Cell wall diameters of 150 cells were measured, 50 cells per field of view. Error bars represent standard deviation. Grey bars represent wildtype plants. Diagonal bars represent empty pGreen7k transformants. Open bars represent single CBM29-2 transformants. Horizontal brick bars represent double CBM29-1-2 transformants

reduced rate of anabolism in the tandem CBM29-1-2expressing plant. It could be that structural remodelling of the cell wall has affected the normal developmental cues that signal the cells to synthesize new cell wall materials. It is conceivable that when the cell walls are held loosely continuously as a result of the continuous presence of CBM29-1-2, the rate of wall extension will outpace biosynthetic rate. Consequently, excessive thinning of the cell walls may occur (Kutschera 1990), which may have led to the eventual collapse of, particularly, the primary walled cells (and not so much of the secondary-walled xylem cells). Thus, because of the extensive loosening of their cell walls and consequent altered expansion, the cortical cells may have yielded to tissue pressure within the stem. The altered cell enlargement, which led to the collapse of the cortical cells of the tandem CBM29-1-2expressing stems, is proposed as the cellular basis for the reduced stem elongation. We have not noticed that the increased size of the xylem cells led to thicker stems. It is possible the gain in the size of the xylem cells is neutralized by the collapse of the cortical cells.

The explanation given above is based on the assumption that the CBMs do not bind to polymers until they have reached the wall. It should be noted, however, that by placing a signal peptide at the amino terminus of the CBMs we have targeted them through the secretory pathway, which includes the site of hemicellulose biosynthesis (the Golgi apparatus) (Denecke et al. 1990; Vitale and Denecke 1999). It is, therefore, possible the CBMs had already bound to hemicellulose before their deposition in the cell wall. As a result, the hemicellulose content, length, and/or branching pattern might have changed; this, in turn, could affect their interaction with cellulose microfibrils, leading to structural alteration of the cell wall.

The expression of the CBM2 $\underline{b}-1-2$ modules in the tobacco cell wall altered the cellular morphology of the transgenic plants, as was apparent from the irregular shape of the cortical cells and altered cell enlargement of the xylem cells of the stems. The deformation of the cortical cells of the CBM2 $-1-2$ expressing plants is, however, less pronounced than that of the cortical cells of the CBM29-1-2 transformants. The more obvious phenotypic changes in the CBM29-1-2-expressing plants is consistent with the result of the immunolabelling study with the proteins, which revealed that CBM29-1-2 binds to polysaccharides that are integral to both primary and secondary cell wall structure. CBM2b-1-2, in contrast, binds only to xylan and non-crystalline cellulose. As xylan is mainly present in the secondary cell wall, it is not strange to see the effect of CBM2 $-1-2$ most pronounced in the secondary walled xylem. The finding that CBM2b-1-2 did not label the cortex (Fig. 2a) suggests that the deformation of the cortical cells is an indirect effect of CBM2 $\underline{b}-1-2$. The cortical parenchyma has no secondary walls, suggesting that the walls are much weaker here; consequently, this tissue might collapse 
when challenged by excessive expansion of flanking tissues. The expression of the CBM2 $\underline{b}-1-2$ only had effect on cellular morphology and not on plant morphology whereas the expression of the CBM29-1-2 in tobacco led to altered structural morphology and altered development of the transgenic plants. The reduced stem elongation phenotype of the CBM29-1-2 tobacco plants is, however, in contrast with the report by Safra-Dassa et al. (2006) of enhanced growth of transgenic potato plants expressing a bacterial CBM3. These contrasting results might be because of the different specificities of the CBMs, because we have used double CBMs in our investigation as opposed to the single CBM they used. That the experiments were performed on different plant species may also have contributed to the different observations.

There are reports attributing cell wall phenotypes in mutant or transgenic plants to abnormal wall assembly in general, or depletion of the cellulose content in particular (Szyjanowicz et al. 2004; Taylor et al. 1999, 2000; Tsabary et al. 2003; Turner and Somerville 1997). In all these instances the plants had deformed walls in vascular cells and reduced growth as a result of cellulose depletion. Our results reveal that wall deformation (cortical cells) can also occur without a marked reduction in cellulose content.

To summarise, the results of our investigation suggest that expression of the promiscuous tandem CBM29-1-2 can alter cell morphology to a larger extent than that of more specific CBM CBM2b-1-2, although the actual effect is unpredictable. Use of CBMs for in-planta cell wall modification thus still needs further investigation.

Acknowledgments The plant cell wall modification project was supported by the Netherlands Foundation for the Advancement of Tropical Research (WOTRO), The Netherlands.

\section{References}

Barral P, Suarez C, Batanero E, Alfonso C, Alche JD, RodriguezGarcia MI, Villalba M, Rivas G, Rodriguez R (2005) An olive pollen protein with allergenic activity, Ole e 10, defines a novel family of carbohydrate-binding modules and is potentially implicated in pollen germination. Biochem J 390:77-84

Bolam DN, Xie HF, White P, Simpson PJ, Hancock SM, Williamson MP, Gilbert HJ (2001) Evidence for synergy between family $2 b$ carbohydrate binding modules in Cellulomonas fimi xylanase 11A. Biochemistry 40:2468-2477

Boraston AB, Bolam DN, Gilbert HJ, Davies GJ (2004) Carbohydrate-binding modules: fine-tuning polysaccharide recognition. Biochem J 382:769-781

Carpita NC, Defernez M, Findlay K, Wells B, Shoue DA, Catchpole G, Wilson RH, McCann MC (2001) Cell wall architecture of the elongating maize coleoptile. Plant Physiol 127:551-565

Charnock SJ, Bolam DN, Nurizzo D, Szabo L, McKie VA, Gilbert HJ, Davies GJ (2002) Promiscuity in ligand-binding: The threedimensional structure of a Piromyces carbohydrate-binding module, CBM29-2, in complex with cello-and mannohexaose. Proc Natl Acad Sci USA 99:14077-14082

Cho HT, Cosgrove DJ (2000) Altered expression of expansin modulates leaf growth and pedicel abscission in Arabidopsis thaliana. Proc Natl Acad Sci USA 97:9783-9788

Choi DS, Lee Y, Cho HT, Kende H (2003) Regulation of expansin gene expression affects growth and development in transgenic rice plants. Plant Cell 15:1386-1398

Compier M (2005) Hemicellulose biosynthesis and degradation in tobacco cell walls. PhD Thesis Wageningen University, The Netherlands

Darley CP, Forrester AM, McQueen-Mason SJ (2001) The molecular basis of plant cell wall extension. Plant Mol Biol 47:179-195

Denecke J, Botterman J, Deblaere R (1990) Protein secretion in plant cell can occur via a default pathway. Plant Cell 2:51-59

Freelove ACJ, Bolam DN, White P, Hazlewood GP, Gilbert HJ (2001) A novel carbohydrate-binding protein is a component of the plant cell wall-degrading complex of Piromyces equi. J Biol Chem 276:43010-43017

Handford MG, Baldwin TC, Goubet F, Prime TA, Miles J, Yu XL, Dupree P (2003) Localisation and characterisation of cell wall mannan polysaccharides in Arabidopsis thaliana. Planta 218:2736

Hellens RP, Edwards EA, Leyland NR, Bean S, Mullineaux PM (2000) pGreen: a versatile and flexible binary Ti vector for Agrobacterium-mediated plant transformation. Plant Mol Biol 42:819-832

Henrissat B, Coutinho PM, Davies GJ (2001) A census of carbohydrate-active enzymes in the genome of Arabidopsis thaliana. Plant Mol Biol 47:55-72

Hosoo Y, Yoshida M, Imai T, Okuyama T (2002) Diurnal difference in the amount of immunogold-labeled glucomannans detected with field emission scanning electron microscopy at the innermost surface of developing secondary walls of differentiating conifer tracheids. Planta 215:1006-1012

Kilburn DG, Warren AJ, Stoll D, Gilkes NR, Shoseyov O, Shani Z (2000) Expression of a mannan binding domain to alter plant morphology. WO 2000/068391 A1

Kuipers AGJ, Soppe WJJ, Jacobsen E, Visser RGF (1995) Factors affecting the inhibition by antisense RNA of granule-bound starch synthase gene-expression in potato. Mol Gen Genet 246:745-755

Kuroiwa T, Kuroiwa H, Mita T, Fujie M (1990) Fluorescence microscopic study of the formation of giant mitochondrial nuclei in the young ovules of Pelargonium zonale. Protoplasma 158:191-194

Kutschera U (1990) Cell-Wall synthesis and elongation growth in hypocotyls of Helianthus annuus L. Planta 181:316-323

Levy I, Shani Z, Shoseyov O (2002) Modification of polysaccharides and plant cell wall by endo-1,4-beta-glucanase and cellulosebinding domains. Biomol Eng 19:17-30

McCartney L, Gilbert HJ, Bolam DN, Boraston AB, Knox JP (2004) Glycoside hydrolase carbohydrate-binding modules as molecular probes for the analysis of plant cell wall polymers. Anal Biochem 326:49-54

McCartney L, Blake AW, Flint J, Bolam DN, Boraston AB, Gilbert HJ, Knox JP (2006) Differential recognition of plant cell walls by microbial xylan-specific carbohydrate-binding modules. Proc Natl Acad Sci USA 103:4765-4770

Pena MJ, Ryden P, Madson M, Smith AC, Carpita NC (2004) The galactose residues of xyloglucan are essential to maintain mechanical strength of the primary cell walls in Arabidopsis during growth. Plant Physiol 134:443-451

Peters WS, Tomos AD (1996) The history of tissue tension. Ann Bot 77:657-665 
Peters WS, Tomos AD (2000) The mechanic state of "Inner tissue" in the growing zone of sunflower hypocotyls and the regulation of its growth rate following excision. Plant Physiol 123:605-612

Pien S, Wyrzykowska J, McQueen-Mason S, Smart C, Fleming A (2001) Local expression of expansin induces the entire process of leaf development and modifies leaf shape. Proc Natl Acad Sci USA 98:11812-11817

Quentin MGE (2003) Cloning, characterisation and assessment of the wall-modifying ability of a fungal cellulose-binding domain. $\mathrm{PhD}$ thesis, Wageningen University, The Netherlands

Ryden P, Sugimoto-Shirasu K, Smith AC, Findlay K, Reiter WD, McCann MC (2003) Tensile properties of Arabidopsis cell walls depend on both a xyloglucan cross-linked microfibrillar network and rhamnogalacturonan II-borate complexes. Plant Physiol 132: $1033-1040$

Safra-Dassa L, Shani Z, Danin A, Roiz L, Shoseyov O, Wolf S (2006) Growth modulation of transgenic potato plants by heterologous expression of bacterial carbohydrate-binding module. Mol Breeding 17:355-364

Schroder R, Wegrzyn TF, Bolitho KM, Redgwell RJ (2004) Mannan transglycosylase: a novel enzyme activity in cell walls of higher plants. Planta 219:590-600

Shoseyov O, Yosef K, Shani Z, Rehovoth, Shpigel E, Medigo K (2001) Transgenic plants of altered morphology. US patent $6,184,440$

Shpigel E, Roiz L, Goren R, Shoseyov O (1998) Bacterial cellulosebinding domain modulates in vitro elongation of different plant cells. Plant Physiol 117:1185-1194

Szyjanowicz PMJ, McKinnon I, Taylor NG, Gardiner J, Jarvis MC, Turner SR (2004) The irregular xylem 2 mutant is an allele of korrigan that affects the secondary cell wall of Arabidopsis thaliana. Plant J 37:730-740

Taylor NG, Laurie S, Turner SR (2000) Multiple cellulose synthase catalytic subunits are required for cellulose synthesis in Arabidopsis. Plant Cell 12:2529-2539

Taylor NG, Scheible WR, Cutler S, Somerville CR, Turner SR (1999) The irregular xylem 3 locus of Arabidopsis encodes a cellulose synthase required for secondary cell wall synthesis. Plant Cell 11:769-780
Tsabary G, Shani Z, Roiz L, Levy I, Riov J, Shoseyov O (2003) Abnormal 'wrinkled' cell walls and retarded development of transgenic Arabidopsis thaliana plants expressing endo-1,4-betaglucanase (cel1) antisense. Plant Mol Biol 51:213-224

Turner SR, Somerville CR (1997) Collapsed xylem phenotype of Arabidopsis identifies mutants deficient in cellulose deposition in the secondary cell wall. Plant Cell 9:689-701

Updegraff DM (1969) Semi-micro determination of cellulose in biological materials. Anal Biochem 32:420-424

van Esse HP, Thomma BPHJ, van't Klooster JW, de Wit PJGM (2006) Affinity-tags are removed from Cladosporium fulvum effector proteins expressed in the tomato leaf apoplast. Journal of Experimental Botany 57:599-608

Vincken JP, Zabotina OA, Beldman G, Voragen AGJ (1998) Xyloglucan endotransglycosylase activities in apples ripeningrelated; implications for fruit juice processing. J Sci Food Agric 78:46-52

Vitale A, Denecke J (1999) The endoplasmic reticulum—gateway of the secretory pathway. Plant Cell 11:615-628

Whitney SEC, Brigham JE, Darke AH, Reid JSG, Gidley MJ (1998) Structural aspects of the interaction of mannan-based polysaccharides with bacterial cellulose. Carb Res 307:299-309

Whitney SEC, Gidley MJ, McQueen-Mason SJ (2000) Probing expansin action using cellulose/hemicellulose composites. Plant J 22:327-334

Whitney SEC, Gothard MGE, Mitchell JT, Gidley MJ (1999) Roles of cellulose and xyloglucan in determining the mechanical properties of primary plant cell walls. Plant Physiol 121:657-663

Wittink FRA, Knuiman B, Derksen J, Capkova V, Twell D, Schrauwen JAM, Wullems GJ (2000) The pollen-specific gene Ntp303 encodes a $69-\mathrm{kDa}$ glycoprotein associated with the vegetative membranes and the cell wall. Sex Plant Reprod $12: 276-284$

Zenoni S, Reale L, Tornielli GB, Lanfaloni L, Porceddu A, Ferrarini A, Moretti C, Zamboni A, Speghini S, Ferranti F, Pezzotti M (2004) Downregulation of the Petunia hybrida alpha-expansin gene PhEXP1 reduces the amount of crystalline cellulose in cell walls and leads to phenotypic changes in petal limbs. Plant Cell 16:295-308 